F. Reprod. Fert. (1975) 43, 175-178

\title{
DESMOSTERYL SULPHATE OF HAMSTER SPERMATOZOA, A POTENT INHIBITOR OF CAPACITATION IN VITRO
}

\author{
G. BLEAU,* W. J. A. VANDENHEUVEL, O. F. ANDERSEN \\ AND R. B. L. GWATKIN† \\ Merck Institute for Therapeutic Research, Rahway, \\ New Jersey 07065, U.S.A.
}

(Received 8th October 1974)

Capacitation of hamster epididymal spermatozoa by the cumulus oophorus in vitro appears to involve glycosidases (Gwatkin \& Andersen, 1973), which act on the spermatozoa while they are bound to sialic acid residues on the cumulus cell membrane (Gwatkin, Andersen \& Hutchison, 1972). Since sterol sulphates are known to stabilize cell membranes (Bleau, Bodley, Longpré, Chapdelaine \& Roberts, 1974) and desmosteryl sulphate (5,24-cholestadiene-3 $\beta$-yl sulphate or DS) was found to constitute $95 \%$ of the sterol sulphate fraction of hamster epididymal spermatozoa (Bleau \& VandenHeuvel, 1974) we determined the effect of this substance on hamster sperm capacitation by cumulus cells in vitro.

Hamster epididymal spermatozoa were extracted with aqueous methanol to isolate DS. This extract was subjected to solvent partitions and thin layer chromatography (Bleau \& VandenHeuvel, 1974). The presence of DS was determined by gas-liquid chromatography-mass spectrometry (Text-fig. 1) on an LKB Model 9000 combination gas chromatograph-mass spectrometer. The chromatogram (see Text-fig. la) resulting from gas-liquid chromatography of an aliquot of the isolated sulphate was identical to that obtained when DS was analysed under the same conditions. The major component (peak of $4.0 \mathrm{~min}$ retention time) is 3,5,24-cholestatriene which arises by a thermal elimination reaction on the column. The mass spectrum (see Text-fig. 1b) of this component from the isolate was obtained by combined gas-liquid chromatography-mass spectrometry and found to be identical to that of authentic 3,5,24-cholestatriene.

The effect of sperm-derived and synthetic DS on capacitation was assessed by the method of Gwatkin \& Andersen (1973). After dissolving in ethanol, the DS was diluted in medium 199M2 and 10- $\mu$ l drops were deposited under mineral oil in a plastic Petri dish. An equal volume of cumulus cells $\left(2 \times 10^{6} / \mathrm{ml}\right)$, dispersed with hyaluronidase, was added to these drops together with $20 \mu \mathrm{l}$ epididymal sperm suspension $\left(10^{7}\right.$ motile spermatozoa $\left./ \mathrm{ml}\right)$. The final concentration of ethanol was $0.25 \%$ in the control as well as in the experimental drops. The Petri dishes were incubated on a rocker for $5 \mathrm{hr}$ at $37^{\circ} \mathrm{C}$. Twenty cumulus-

* Present address: Montreal Cancer Institute, Notre Dame Hospital, Montreal, Quebec, Canada. † Reprint requests to Dr R. B. L. Gwatkin. 

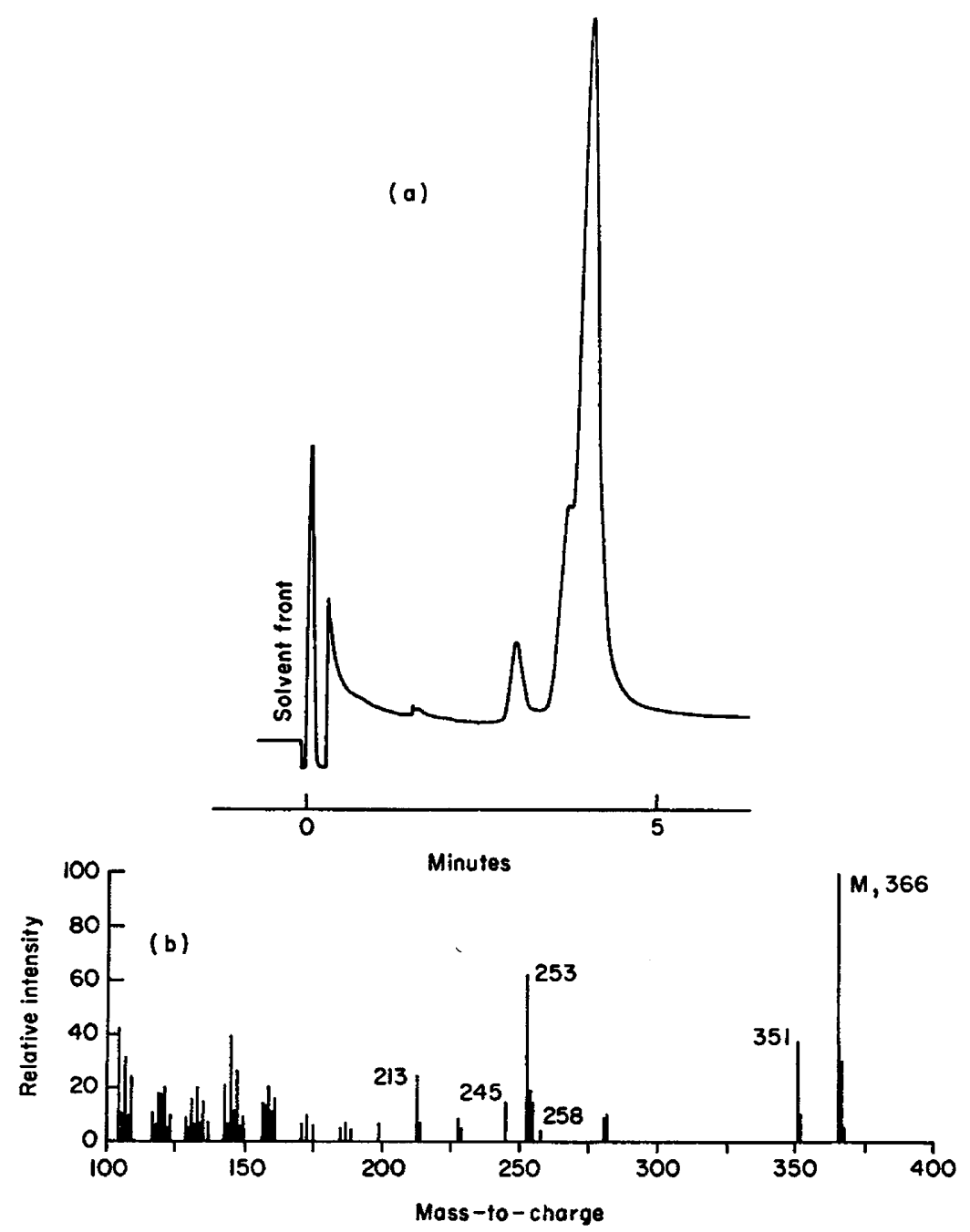

Text-Fig. 1. (a) Chromatogram resulting from gas-liquid chromatography of hamster sperm extract. The sterol sulphate fraction was dissolved in methanol and analysed on a $1 \%$ OV-17 column at $200^{\circ} \mathrm{C}$. (b) The mass spectrum, recorded during the elution of the major peak using the spectrometer conditions : ionizing potential, $70 \mathrm{eV}$; filament current, $60 \mu \mathrm{A}$; source temperature, $270^{\circ} \mathrm{C}$; accelerating potential $3.5 \mathrm{kV}$. The mass-to-charge value for the molecular ion of 3,5,24-cholestatriene $(M)$ is 366 , indicating a mol. wt of 366.

free eggs were then added to each drop and sperm penetration into these eggs was scored $90 \mathrm{~min}$ later.

Capacitation in the sperm extracts was blocked by DS at dilutions up to $1 / 5000$. Text-figure 2 shows the results obtained with synthetic DS. The proportion of eggs penetrated was reduced $50 \%$ by $5 \times 10^{-16} \mathrm{M}$-DS and no penetration at all occurred at $10^{-12} \mathrm{M}$. Free desmosterol and cholesterol at $10^{-8} \mathrm{M}$ did not affect capacitation, as judged by the proportion of eggs penetrated.

To inhibit capacitation completely it was necessary to add DS $\left(10^{-9} \mathrm{M}\right)$ at 


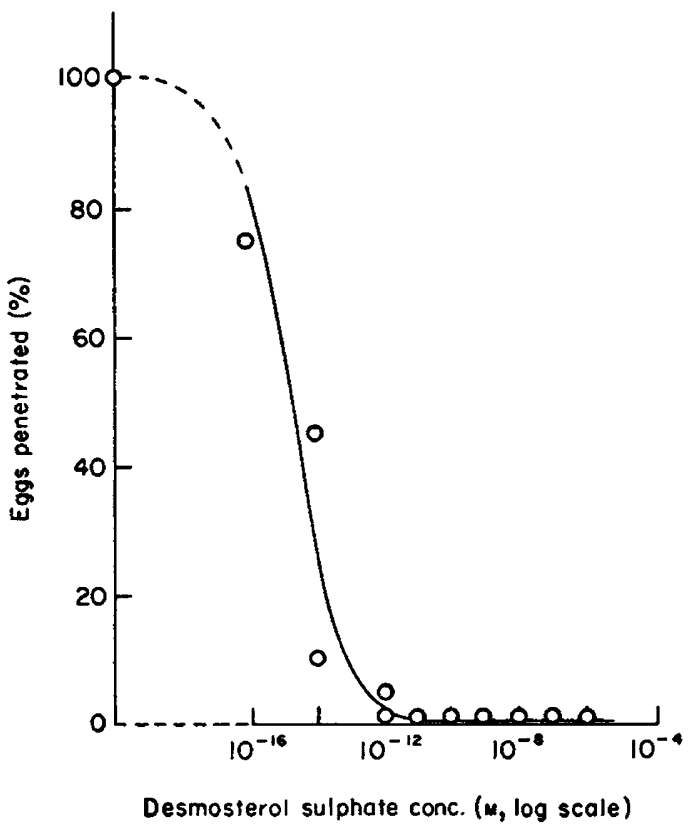

TExT-FIG. 2. Inhibition of capacitation of hamster spermatozoa in vitro by synthetic desmosteryl sulphate.

Table 1. Effect of desmosteryl sulphate $\left(10^{-9} \mathrm{M}\right)$ on the capacitation of hamster spermatozoa by cumulus cells in vitro

\begin{tabular}{ccc}
\hline & \multicolumn{2}{c}{$\%$ Ova penetrated } \\
\cline { 2 - 3 } Time of addition & Control & Desmosteryl sulphate \\
$($ hr $)$ & & \\
\hline 0 & 80 & 0 \\
1 & 90 & 40 \\
2 & 80 & 60 \\
3 & 90 & 60 \\
4 & 100 & 90 \\
5 & 90 & 100 \\
\hline
\end{tabular}

the start of incubation (Table 1). If the DS was added $1 \mathrm{hr}$ later, it only partly inhibited the proportion of eggs penetrated. When the compound was added after 4 to $5 \mathrm{hr}$, it was ineffective. This result also shows clearly that DS has no effect on sperm penetration of the eggs once capacitation has occurred.

When cumulus cells were washed and then assayed in the presence of matrix, their capacitation ability was unimpaired. This confirms previous results (Gwatkin et al., 1972). Exposure for $30 \mathrm{~min}$ to $10^{-10} \mathrm{M}$-DS before washing, however, completely inhibited capacitation. This result indicates that action on the cells alone is sufficient to prevent capacitation.

Gwatkin \& Williams (1970) and Briggs (1973) earlier reported that a number of steroids, including oestradiol and various synthetic progestagens, inhibit 
hamster sperm capacitation by cumulus cells in vitro, but none of these compounds was effective at concentrations less than $10^{-4}$ to $10^{-5} \mathrm{M}$. Non-sulphated steroids are not as effective as sulphated steroids in stabilizing cell membranes (Bleau et al., 1974) and it may be for this reason that they are so much less effective than DS in blocking capacitation. It is also possible that DS competitively inhibits the sterol sulphatase which is present in cumulus cells (G. Bleau and R. B. L. Gwatkin, unpublished results) and in the human Fallopian tube (Bleau, 1972). This enzyme could be involved in altering or removing sperm DS and constitute a part of the capacitation process induced by the cumulus oophorus.

\section{REFERENGES}

BlEAU, G. (1972) Biochemie du sulfate de cholesterol. Ph.D. dissertation, Faculty of Medicine, University of Montreal.

Bleau, G., Bodley, F., Longree, J., Ghapdelaine, A. \& Roberts, K. D. (1974) Gholesterol sulfate. I. Occurrence and possible biological function as an amphipathic lipid in the membrane of the human erythrocyte. Biochim. biophys. Acta, 352, 1-8.

Bleau, G. \& VandenHeuvel, W. J. A. (1974) Desmosteryl sulfate and desmosterol in hamster epididymal spermatozoa. Steroids, 24, 549-556.

BRIGGs, M. H. (1973) Steroid hormones and the fertilizing capacity of sperm. Steroids, 22, 547-553.

Gwatkin, R. B. L. \& ANDERsen, O. F. (1973) Effect of glycosidase inhibitors on the capacitation of hamster spermatozoa by cumulus cells in vitro. 7 . Reprod. Fert. 35, 565-567.

Gwatkun, R. B. L., Andersen, O. F. \& Hutchison, G. F. (1972) Gapacitation of hamster spermatozoa in vitro: the rôle of cumulus components. 7. Reprod. Fert. 30, 389-394.

Gwatkin, R. B. L. \& Williams, D. T. (1970) Inhibition of sperm capacitation in vitro by contraceptive steroids. Nature, Lond. 227, 183. 